\title{
WHICH COMMODITY TAXES SHOULD SUPPLEMENT THE INCOME TAX?
}

\author{
Vidar CHRISTIANSEN* \\ University of Oslo, Blindern, Oslo 3, Norway
}

Received July 1981, revised version received October 1983

\begin{abstract}
The analysis takes as its point of departure a continuum of consumers economy in which an optimum income tax exists and is the only tax instrument in operation. The welfare effects of introducing small excise taxes to supplement the income tax are then explored. Essential in this context are changes in the tax distortions of work incentives. It is shown that a commodity should be taxed or subsidized depending on whether it is positively or negatively related to leisure in a sense which is precisely defined. The results are related to earlier contributions to the literature on direct versus indirect taxation.
\end{abstract}

\section{Introduction}

The history of debates on the proper roles of direct and indirect taxation goes back at least to the days of Gladstone, as well described by Atkinson (1977). The prevailing political opinion of the balance between the two types of taxes has varied over time. At present the swing in a number of European countries seems to be in favour of reforms towards tax systems which rely more heavily on indirect taxation and less on income taxation. In view of this long economic-political record, it is not surprising that the choice between income tax and commodity taxes has also become an important subject in tax theory.

An early contribution to the understanding of this issue was Corlett and Hague (1953-54). Their main model considers a three-good economy, containing leisure and two taxed commodities. There is only one consumer (or a population of identical consumers). Labour is the only source of income. Producer prices are fixed. The government's revenue requirement is given. The starting point of the analysis is a situation in which the two commodities are taxed at uniform rates. The question which is analyzed is then how the government can raise welfare by slightly differentiating the tax rates. The answer which is derived is that the consumer good which is the stronger substitute for labour (complement with leisure) should be taxed at

\footnotetext{
*Previous versions of this paper have been presented at seminars at the University of Bergen and the University of Stockholm. I am indebted to seminar participants, to Tony Atkinson, Søren Blomquist, Kåre P. Hagen, Agnar Sandmo and the referees for valuable comments and suggestions.
} 
the higher rate. The degree of substitutability (or complementarity) can be measured by the compensated cross-elasticity with labour (leisure). It is intuitively easy to grasp the essence of this result. As expressed by Sandmo (1976): 'The economic rationale of this rule is clearly that since we have barred ourselves from taxing leisure, we can do it indircctly by taxing commodities that are complementary with liesure.'

As Corlett and Hague put it: 'the main analysis considers small changes in tax rates and does not indicate the size of the movements away from the initial equilibrium position needed to obtain an "optimum" system of taxation'. Thus, it may be considered as an early contribution to what is now known as tax reform analysis. But, as has been shown, the same result is valid at optimal taxation; see for example Sandmo (1976).

It is important to note, as was emphasized by Corlett and Hague, that taxation of the two consumer goods at uniform rates is equivalent to a proportional income tax. Deviation from uniform tax rates is therefore equivalent to the introduction of an excise tax in addition to a proportional income tax. In this sense the model is suitable for throwing light on the income versus commodity tax issue. Although the model is rather special, it may be argued that the insight obtained is rather basic.

Meade (1955) discussed the role of commodity taxes as a supplement to the income tax within a more general, but purely non-mathematical framework. He allows the income tax schedule to have a more general form, and the taxpayers may have unequal income. His approach is clearly described in his own words:

We assume, therefore, that the revenue is being raised by a progressive income tax which, as explained on p. 47, introduces throughout the system a large rate of divergence between the value of the marginal product of effort and the marginal cost of that effort.... The question which we shall discuss is whether, given this situation, it would be desirable to turn to some extent from the direct taxation of income to the indirect taxation of particular goods and services as a means of raising revenue [Meade (1955, p. 112)].

His reasoning leads him to the conclusion that a welfare improvement would be obtained by making a small marginal change in the tax system which raises the price of those things which are jointly demanded with leisure, and lowers the price of those things which are good substitutes for leisure, provided that seriously adverse effects on the distribution of income are avoided. This is a result which is very close to that of Corlett and Hague. It is, however, less precise, as one might expect from a non-mathematical analysis. In particular the substitute concept is not precisely defined. Meade's analysis deals with the welfare effects of 'a small marginal change in the tax system'. Thus, his analysis may also be considered as an early contribution to tax reform theory. 
A third important contribution to the literature on direct versus indirect taxation is Atkinson and Stiglitz (1976). In their analysis the taxpayers are assumed to have homogeneous preferences, but different wages. Optimality characteristics of simultaneous non-linear schedules for income and commodity taxes are derived. These characteristics are related to the properties of the taxpayers' common utility function. It turns out that whether a good is complementary with or a substitute for leisure in the Edgeworth sense (defined by the sign of the cross derivative of the utility function) is crucial in determining the excise tax to be imposed on it. The great merit of the paper was to show that if the utility function is weakly separable between labour and all goods taken together, then there is no need to employ indirect taxation in the optimum solution.

A fourth key paper to be mentioned in this field is Mirrlees (1976) which derived conditions for optimal mixed taxation consisting of optimal tax schedules and rates. Some details of this paper will be discussed in section 8 .

The existing body of optimum tax literature has obviously a good deal to say about the optimal choice of indirect taxes in addition to the income tax. Yet economists who want to apply these theories, for instance as political advisers, do encounter a number of problems. One reason is that modern optimum tax results are often given in such a form that they are hard to convey to the layman on the political scene or elsewhere. ${ }^{1}$ There is obviously a need for simpler characteristics of optimal tax policy. In older analyses of commodity taxes such as Corlett and Hague (1953-54) and Meade (1955) the key to understanding the role of commodity taxes is presented in terms of substitutability and complementarity between leisure and consumer goods. No doubt this approach has a strong intuitive appeal both to the expert and the layman. In recent and technically more complicated optimum tax theory the possible roles of substitutes and complements are much less exposed or even left completely in the dark, in my opinion at the expense of intuitive insight. This is also onc reason why the connection between the various analyses included in the brief survey above is not easy to see, although one would suspect that they are closely related. In particular one would expect the simple implications of the older analyses to be embodied in some form in the more complicated results of modern theories. Further exploration of this subject therefore seems worthwhile.

The first purpose of this paper is to provide a mathematical and more precise analysis of the problem formulated and discussed by Meade (1955). In order to define the starting-point more precisely than was done by Meade, the shape of the initial income tax schedule is assumed to have been optimized by a welfare-maximizing government. The analysis will then examine how welfare can be raised even further by turning slightly from income taxation to the taxation of particular commodities. This will allow us

\footnotetext{
${ }^{1}$ An exposition aiming at a larger public is found in Atkinson (1977).
} 
to review the Meade results in a precise manner. It also paves the way for the second task, which is to relate the Meade type results to those of Atkinson and Stiglitz (1976) and Mirrlees (1976). The third and closely related purpose is to focus attention on the roles of various relations between lcisure and the demand for other goods, which I believe to be most helpful guides to the understanding of theoretical results in this field of tax analysis. In contrast to a lot of modern tax literature the technical analysis is going to be rather simple.

It may be useful to give a preliminary idea of the approach to be followed as it deviates somewhat from the standard analysis. The behaviour of the consumer/taxpayer is assumed to be ordinary maximizing behaviour both in the commodity and labour market. But for analytical reasons it is useful to treat it here as a two-stage optimization whereby the demand for consumption goods is optimized for a given supply of labour in the first stage, and the supply of labour is optimized in the second stage taking into account the relations between commodity demand and labour supply established in the first stage. This approach will enable us to extend the tradition of making use of relations between the demand for various goods and labour supply in throwing light on the choice of excise laxes. The income tax will be treated in an analytically simple manner by applying a tax function with a shift parameter which allows us to carry out a shift in the whole tax schedule to accompany the introduction of an excise tax.

The main assumptions underlying the analysis to follow are presented in section 2. Individual behaviour is described in section 3, and section 4 briefly presents the optimum income tax. The analysis of marginal commodity taxes in section 5 is the main part of the current paper. Section 6 discusses the roles of substitutes and complements. Sections 7 and 8 provide comparisons with the results of Atkinson and Stiglitz and those of Mirrlees. Section 9 takes a closer look at the treatment of leisure goods. Section 10 presents some concluding remarks and also draws attention to some of the limitations of the preceding analysis.

\section{Main assumptions}

The analysis will be based on a number of assumptions which have become common in modern optimum tax literature (including the above references). A one-period model (or timeless economy) is considered. This is important because we have then barred ourselves from discussing effects on savings behaviour which might be interesting. Individuals are assumed to have identical preferences on consumption bundles and work effort (leisure). Work is the only source of income apart from possible government transfers.

The wage rate of each person is exogenous and determined by his ability. It is then convenient to consider the ability level and the wage rate as equal. 
There is a continuum of individuals distributed by ability (wage rate). The distribution is characterized by the density function $f(a)$, where $a$ is the ability level which is taken to be positive. Producer prices are given. There is no tax evasion.

Each person chooses his work effort and consumption bundle optimally taking his own ability, the prices and the tax policy as given. This individual behaviour, which is analysed in the next section, is taken as given by the government when designing its tax policy. The revenue requirement is given. An additive welfare function is used as welfare criterion.

\section{Individual behaviour}

We study an individual who does an amount $h$ of work at a given wage rate, $a$ (reflecting his ability). His gross income is:

$$
I=a h .
$$

He faces an income tax schedule $T(I)$, so that his disposable income becomes:

$$
y=I-T(I)=a h-T(a h)
$$

This income is spent on $n$ consumer goods in quantities $x_{1}, \ldots, x_{n}$ at prices $P_{1}, \ldots, P_{n}$. Let $x$ and $P$ denote the consumption vector and price vector, respectively. The scalar product of the two vectors is written as $P x$. Preferences are described by the utility function $u(x, h)$. The individual is assumed to maximize $u$ as a price-taker subject to his budget constraint. As suggested above, it will prove useful to conceive of this maximization as being carried out in two stages. First the work effort, $h$, is treated as fixed, and $u$ is maximized with respect to $x$. We establish the Lagrange expression:

$$
L=u(x, h)-\omega(P x-y),
$$

and derive the well-known necessary first-order conditions:

$$
\begin{aligned}
& \frac{\partial L}{\partial x_{i}}=u_{i}(x, h)-\omega P_{i}=0, \quad i=1, \ldots, n . \\
& P x-y=0 .
\end{aligned}
$$

Partial derivatives are indicated by appropriate subscripts. These conditions define a special kind of demand functions:

$$
x_{i}(P, y, h), \quad i=1, \ldots, n .
$$


Adopting the terminology of Pollak (1969), we may call them conditional demand functions since they express the demand for consumer goods conditional upon the value of $h . \partial x_{i} / \partial h$ is the marginal effect on the demand for good $i$ of an increase in work effort when disposable income, $y$, is somchow kept constant. The corresponding conditional indirect utility function may be written as:

$$
v(P, y, h)=u(x(P, y, h), h)
$$

where $x(\cdot)$ is a vector function.

We know from duality theory that:

$$
\begin{aligned}
& v_{i}=-\omega x_{i}, \quad i=1, \ldots, n, \\
& v_{y}=\omega, \\
& v_{h}=u_{h} .
\end{aligned}
$$

Subscripts $y$ and $h$ indicate partial derivatives with respect to these arguments, respectively. The second stage of the optimization is to maximize (7) with respect to $h$ taking into account that $y$ is a function of $h$. Provided that the income tax function is differentiable, the first-order condition for an interior optimum is:

$$
v^{\prime}=\frac{\mathrm{d} v}{\mathrm{~d} h}=v_{y}(P, y, h) a\left(1-T^{\prime}(a h)\right)+v_{h}(P, y, h)=0,
$$

where the marginal income tax is denoted by $T^{\prime}=\mathrm{d} T / \mathrm{d} I$. The differentiability assumption will be discussed in more detail below.

The second-order condition is:

$$
v^{\prime \prime}<0
$$

For given prices and tax schedule $h, x, I, v$ and $\omega$ become functions of the wage rate or ability parameter, $a$. We denote the (unconditional) indirect utility function by $V(a)$.

\section{The optimal income tax}

We shall explore the effect on welfare of switching slightly away from pure income taxation to the combined taxation of income and some commodity. As it seems natural to exhaust the opportunities for welfare improvements within the original system before introducing a new tax instrument, we shall 
assume that the initial income tax has got an optimal design. We can then benefit from making use of the optimality characteristics. In particular it will allow us make use of the envelope properties.

The optimal income tax has been analysed in a number of papers [see, for example, Mirrlees (1971, 1976, 1977)], and we shall not go into details in the present context. It is not the purpose of this paper to extend the analysis of the pure income tax. On the contrary, we shall make assumptions about the optimal tax schedule (differentiability, etc.) which mean that we have to be somewhat modest about the generality of the analysis. The analysis of the optimal income tax is a complicated piece of mathematical economics. The optimization problem is usually formulated as an optimum control problem. But, as emphasized by Mirrlees (1977), it is hard to tell, because of the special nature of the problem, when the optimum is characterized by the standard first-order conditions usually found in the literature. In particular, it may be dubious to represent the individual optimization simply by the firstorder conditions of that problem in the social optimization. It is not the aim of this paper to take up these mathematical problems which apply to a wider class of optimum tax problems than the one presented here.

The analysis will be based on a number of crucial differentiability assumptions without which the analysis becomes much more complicated. First, the tax function itself is assumed to be differentiable. This may not be true in general, as pointed out by Mirrlees (1971). As we shall see, the assumption has got important implications. The budget set corresponding to a particular tax schedule and the consumption points chosen by different individuals are often illustrated in an $I, y$-diagram. For a given wage (ability), $a$, indifference curves can be drawn on this diagram to illustrate the trade-off between gross income and net income and hence the consumption-leisure trade-off of an $a$-individual. One such indifference curve is shown in fig. 1 . We shall adopt the common assumption that an individual with a higher ability has a flatter indifference curve through any given point $(I, y)$ than an individual with a lower ability. [See Seade (1982).] With this assumption it is obvious that individuals on different ability levels can have the same consumption point only if this is a corner point of the budget set. With corners ruled out by the differentiability assumption, gross income becomes a strictly increasing function of the individual wage-rate except for possible wage-rates at which no labour is supplied. Let $I(a)$ denote this relationship. [For more details see Seade (1982).]

In the following analysis we shall make use of shifts in the tax function. Introducing a shift parameter $S$ we obtain an income tax function $T(I, S)$. It is common to assume that the economic variables are differentiable functions of the ability parameter $a$. [See, for example, Mirrlees (1976).] In the current analysis it is an essential assumption that the economic variables are differentiable with respect both to $a$ and $S$. These assumptions are to some 
extent related. In general one of the problems encountered in tax optimization (in particular with a finite population) is that some consumers may be left indifferent among widely different consumption bundles. If this were the case, a small change in a might lead to discontinuous jumps in consumption points. In that case a small change in the tax schedule is also likely to produce discrete shifts of consumption points.

The case is illustrated in fig. 1. It shows the budget curve $(B-B)$ resulting from a particular tax schedule and the indifference curve $\left(I^{\prime}-I^{\prime}\right)$ for a person of ability $a^{\prime}$. As the figure has been drawn, this person is indifferent between point $P$ and point $Q$. With the usual assumption that people with higher ability have flatter indifference curves, people with $a$ greater than $a^{\prime}$ will be to the right of $Q$ and people with lower $a$ than $a^{\prime}$ will be to the left of $P$. Thus, there will be a discrete jump. If the $a^{\prime}$-person is initially at $P$, and a marginal shift in the budget curve takes place which makes it slightly less favourable at and around $P$, the person will move his consumption point discretely to $Q$. Such discrete shifts are not permitted in the current analysis. Differentiability is crucial.

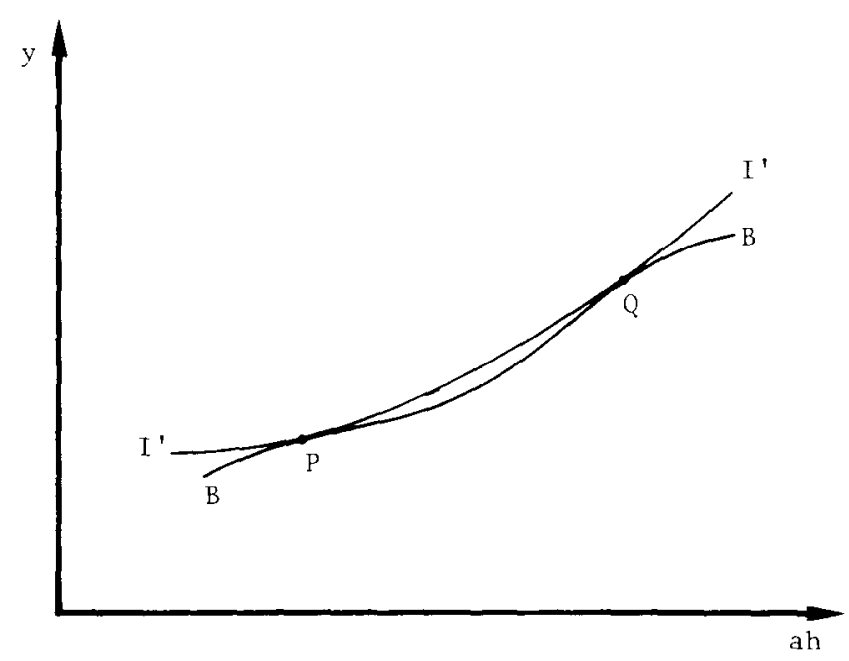

Fig. 1.

Let us now turn to our characterization of the optimal income tax. We start out by considering the situation in which a general income tax is the only tax instrument of the government. When designing its tax policy the government must take into account the whole population of individuals, each following the behaviour described above, and the ability distribution $f(a)$. A total tax revenue amounting to $T^{0}$ is required. The government must then choose its tax policy within the budget constraint 


$$
\int T(I(a)) f(a) \mathrm{d} a=T^{0},
$$

where the size of the population has been normalized at unity. ${ }^{2}$ The shape of the tax schedule is chosen so as to maximize

$$
W=\int V(a) f(a) \mathrm{d} a
$$

subject to (13).

It is not the concern of this paper to characterize in detail the optimum shape of the income tax function. A rather compact characterization will do for our purpose. Let us therefore assume that the optimal shape of the income tax function has been determined up to a number of parametric shifts. The last part of the optimization can then be carried out by means of usual parametric optimization. In order to do this we make use of the shift parameter $S$ in the income tax function, $T(I, S)$. A shift is generated by changing $S$. It is denoted by $T_{S}=\partial T / \partial S$. Let us also assign the shadow price $\mu$ to the tax revenue constraint (13). The tax function can then be optimized with respect to $S$ by means of the standard Lagrange expression

$$
L=\int V(a, S) f(a) \mathrm{d} a+\mu\left(\int T(a h, S) f(a) \mathrm{d} a-T^{0}\right) .
$$

The first order condition can then be expressed as

$$
\frac{\mathrm{d} L}{\mathrm{~d} S}=-\int \omega T_{S} f \mathrm{~d} a+\mu \int T_{S} f \mathrm{~d} a+\mu \int T^{\prime} a h_{S} f \mathrm{~d} a=0,
$$

where we have used the fact that $\partial V / \partial S=-\omega T_{S}$, which is easily established by applying the envelope theorem to (7). The second and third term of the left hand side express the resulting change in tax revenue evaluated by means of $\mu$. The Lagrange multiplier has the usual interpretation:

$$
\mu=-\partial W / \partial T^{0} \text { evaluated at the optimum. }
$$

At the optimum an arbitrary marginal shift in the tax function must neither lower nor raise welfare, otherwise a shift could always be devised which would increase welfare, and it follows that the initial schedule would not have been optimal.

In order to be able to differentiatc $h$ with respect to $S$, as done in expression (16), our differentiability assumptions are obviously essential. As discussed above, a situation such as the one depicted in fig. 1 might lead to discrete jumps in the consumption point in response to a marginal shift in the tax schedule. It is important that such cases have been ruled out.

${ }^{2}$ For simplicity integration limits are omitted. 
A shift parameter, $S$, can obviously be used to express any shift in the tax function from the optimal one. To see this let $T^{*}(I)$ be the optimal tax function, and let $F(I)$ be some arbitrary function of $I$. The income tax function can generally be written as $T(I, S)=T^{*}(I)+S F(I)$. The optimum value of $S$ is obviously zero, and a small change in $S$ will generate a marginal shift, of which the first-order effect on welfare is zero.

\section{Marginal commodity taxes}

Let $p_{1}, \ldots, p_{n}$ denote the fixed producer prices per unit of $x_{1}, \ldots, x_{n}$, respectively, and let $p$ denote the corresponding price vector. Suppose that commodity taxes may be levied as taxes $t_{1}, \ldots, t_{n}$ per unit of $x_{1}, \ldots, x_{n}$, respectively. Let $t$ denote the corresponding vector. Negative taxes are allowed, which means that commodities may be subsidized.

We are now prepared to consider the introduction of marginal excise taxes to supplement the optimal income tax. What commoditics should then be (positively) taxed, left untaxed or subsized, respectively?

It should be noted at this stage that proportional taxation of all commodities is obviously equivalent to a proportional income tax. So this possibility is already covered by assuming the existence of an optimal initial income tax. The question we are asking is therefore: What commodities should be taxed if differentiated indirect taxes may be imposed?

In order to deal with commodity taxes, we must write the tax revenue constraint as

$$
\int T(a h, S) f \mathrm{~d} a+\int t x f \mathrm{~d} a-T^{0}=0 .
$$

The special case $t_{1}=t_{2}=\ldots=t_{n}=0$ takes us back to (13) and the results of the preceding section, which we now take as our point of departure. ${ }^{3}$ The imposition of marginal unit tax rates $t_{1}, \ldots, t_{n}$ can now be analysed by applying the envelope theorem to the Lagrange expression:

$$
L=\int v(P, y, h) f \mathrm{~d} a+\mu\left(\int \Gamma(a h, S) f \mathrm{~d} a+\int t x f \mathrm{~d} a-T^{0}\right) .
$$

Making use of (8) and bearing in mind that $P_{i}=p_{i}+t_{i}$ and $t_{i}=0$ for all $i$, we find that:

$$
\frac{\partial W}{\partial t_{i}}=-\int \omega x_{i} f \mathrm{~d} a+\mu \int x_{i} f \mathrm{~d} a+\mu \int T^{\prime} a h_{\mathrm{t}_{i}} f \mathrm{~d} a, \quad \forall i
$$

where $h_{t_{i}}=\partial h / \partial t_{i}$.

${ }^{3}$ The exposition is simplified by omitting the arguments of the functions where no confusion is likely to arise. The reader should bear in mind that $h=h(a, S, t), y=a h-T(a h, S), x_{i}=x_{i}(a, S, t)$, and $f=f(a)$. 
Let us now pick one good, say good 1 , for further consideration. How a small excise tax on good 1 would affect social welfare depends on the sign of

$$
\frac{\partial W}{\partial t_{1}}=-\int \omega x_{1} f \mathrm{~d} a+\mu \int x_{1} f \mathrm{~d} a+\mu \int T^{\prime} a h_{t_{1}} f \mathrm{~d} a .
$$

Eq. (21) expresses the welfare effect of levying a marginal commodity tax on commodity 1 without changing total tax revenue. The first term of (21) captures the immediate effect of the tax burden imposed by the new tax while the second and third term together capture the effect of the ensuing tax changes which are required to keep total tax revenue unaltered.

There is not much to say on the basis of (21). Further manipulation is obviously necessary to be able to arrive at policy recommendations. The first thing we do is to define a marginal shift in the income tax function of which the immediate effect is to impose a tax increase $x_{1}$ on each taxpayer. Formally:

$$
T_{\mathrm{S}}=x_{1} .
$$

This analytical trick is a crucial point which may require a more detailed explanation. Since the income tax is a function of gross income, and the function must be the same for everybody, it is only admissible to define such a shift if $x_{1}$ can be expressed as a function of gross income alone. Taking the initial income tax function as given, and recalling that preferences are uniform across individuals, the individual decision variables ultimately become functions of the wage-rate only. We can therefore express $x_{1}$ as a function $x_{1}(a)$ which is the initial relationship between $x_{1}$ and $a^{4}$ Moreover, as we have seen already, gross income is a strictly increasing function of $a$ which can be inverted so that $a$ becomes a function of $I$. Inserting this relationship into $x_{1}(a)$ we obtain a function $x_{1}^{*}(I)$ which is exactly the kind of relationship which allows us to write eq. (22). We can now write $T(I, S)=T^{*}(I)+S x_{1}^{*}(I)$. Hence, the shift is well defined for all $I$.

Our differentiability assumptions are crucial at this stage. If the tax schedule were kinked, there would be people with different wage-rates and different consumption bundles earning the same income. Then there would not be a unique value of $x_{1}$ associated with each value of $I$, and (22) would not be a meaningful definition of a shift in the income tax function.

The reader should not be confused by the fact that $I=a h$ is a variable in the tax function, while we also write $h$ as a function of $S$. A change in $S$ changes the tax associated with each value of $I=a h$. This is a quite ordinary shift. But, since the individual will normally respond to the shift in the tax

\footnotetext{
${ }^{4} x_{i}$ is used as a function symbol both in $x_{i}(P, y, h)$ and $x_{i}(a)$ since this is not likely to cause any confusion.
} 
schedule by changing his consumption point, the chosen value of $h$ (or $I$ ) depends on $S$. The actual change in the tax paid by an individual is the combined effect of a shift in the tax function and a movement along the tax schedule. This is analogous to a shift in an ordinary partial demand function which implies that we can write the price as a function of the shift parameter.

Since (16) is true for any marginal shift in the tax function from the initial optimum, it is also valid for the shift defined by (22). Hence, if we substitute $x_{1}$ for $T_{S}$ in (16):

$$
-\int \omega x_{1} f \mathrm{~d} a+\mu \int x_{1} f \mathrm{~d} a+\mu \int T^{\prime} a h_{S} f \mathrm{~d} a=0,
$$

or:

$$
-\int \omega x_{1} f \mathrm{~d} a+\mu \int x_{1} f \mathrm{~d} a=-\mu \int T^{\prime} a h_{S} f \mathrm{~d} a .
$$

Inserting this expression into (21) we obtain:

$$
\frac{\partial W}{\partial t_{1}}=\mu \int T^{\prime} a\left(h_{t_{1}}-h_{S}\right) f \mathrm{~d} a .
$$

Now the complexity of the formula has been reduced, and we can approach the problem of signing. In general $\left(h_{t},-h_{S}\right)$ can be of any sign, and the question is whether positive terms outweigh the negative ones or vice versa. A more interesting approach is to ask whether there are classes of utility functions or demand patterns which ensure sufficiently unambiguous reactions across individuals to guarantee a unique sign. Indeed, we know of one such case already from the weak separability result of Atkinson and Stiglitz (1976).

Since $\mu, T^{\prime}, a$ and $f$ are all positive, what we want to explore is the sign of $\left(h_{t_{1}}-h_{S}\right)$. The effect of $t_{1}$ on $h$ is obtained from the optimality condition (11):

$$
v_{y}(p+t, a h-T(a h, S), h) a\left(1-T^{\prime}(a h, S)\right)+v_{h}(p+t, a h-T(a h, S), h)=0 .
$$

Differentiating with respect to $t_{1}$ we find:

$$
v^{\prime \prime} h_{t_{1}}+a\left(1-T^{\prime}\right) v_{y_{1}}+v_{h_{1}}=0
$$

and hence:

$$
h_{t_{1}}=\frac{1}{v^{\prime \prime}}\left(\frac{v_{h}}{v_{y}} v_{y 1}-v_{h 1}\right) \text {, }
$$

where (11) has again been applied. $h_{S}$ is found in a similar way by differentiating (11): 


$$
v^{\prime \prime} h_{S}+a\left(1-T^{\prime}\right) v_{y y}\left(-T_{S}\right)+v_{y} a\left(-\frac{\partial T^{\prime}}{\partial S}\right)-v_{h y} T_{S}=0
$$

A number of substitutions can be made by means of the relations: ${ }^{5}$

$$
T_{S}=x_{1}=-\frac{v_{1}}{v_{y}}, \quad \frac{\partial T^{\prime}}{\partial S}=\frac{\partial T_{S}}{\partial I}=\frac{\partial x_{1}}{\partial I}=-\frac{\partial\left(v_{1} / v_{y}\right)}{\partial I} .
$$

We find that:

$$
h_{S}=\frac{1}{v^{\prime \prime}}\left[\frac{v_{h}}{v_{y}} v_{y y} \frac{v_{1}}{v_{y}}-v_{h y} \frac{v_{1}}{v_{y}}-v_{y} a \frac{\partial}{\partial I}\left(\frac{v_{1}}{v_{y}}\right)\right] .
$$

Since $y$ and $h$ are functions of $a$, and, as we have seen, $a$ can be expressed as $a(I)$, we can write:

$$
x_{1}(P, y, h)=x_{1}(P, y(I), h(I))=-v_{1}(P, y(I), h(I)) / v_{y}(P, y(I), h(I)),
$$

which hold at the initial equilibrium where $S=t_{1}=0 .{ }^{6}$ Hence we find that:

$$
\begin{aligned}
a \frac{\partial x_{1}}{\partial I} & =-a \frac{\partial}{\partial I}\left(\frac{v_{1}}{v_{y}}\right)=-a \frac{\partial}{\partial y}\left(\frac{v_{1}}{v_{y}}\right) \frac{\partial y}{\partial I}+a \frac{\partial x_{1}(P, y, h)}{\partial h} \frac{\partial h}{\partial I} \\
& =-\left(\frac{v_{1} y}{v_{y}}-\frac{v_{1} v_{y y}}{v_{y}^{2}}\right)\left(1-T^{\prime}\right) a+\frac{\partial x_{1}(P, y, h)}{\partial h} a \frac{\partial h}{\partial I}
\end{aligned}
$$

and due to (11):

$$
-a \frac{\partial}{\partial I}\left(\frac{v_{1}}{v_{y}}\right)=\left(\frac{v_{1 y}}{v_{y}}-\frac{v_{1} v_{y y}}{v_{y}^{2}}\right) \frac{v_{h}}{v_{y}}+\frac{\partial x_{1}(P, y, h)}{\partial h}-a \frac{\partial h}{\partial I} .
$$

This result simplifies (28) so that:

$$
h_{S}=\frac{1}{v^{\prime \prime}}\left(\frac{v_{1 y} v_{h}}{v_{y}}-\frac{v_{h y} v_{1}}{v_{y}}+v_{y} \frac{\partial x_{1}(P, y, h)}{\partial h} a \frac{\partial h}{\partial I}\right) .
$$

$\Lambda$ pplying (25) and (30):

$$
h_{t_{1}}-h_{S}=\frac{1}{-v^{\prime \prime}}\left(v_{t_{1}}-\frac{v_{h y} v_{1}}{v_{y}}+v_{y} \frac{\partial x_{1}(P, y, h)}{\partial h} a \frac{\partial h}{\partial I}\right) .
$$

${ }^{5}$ Recall that $T(I, S)=T^{*}(I)+S x_{1}^{*}(I)$. Hence, $T^{\prime}(I, S)=\partial T^{*} / \partial I+S \partial x_{1}^{*} / \partial I$, and $\partial T^{\prime} \partial S=\partial x_{1}^{*} / \partial I$.

${ }^{6}$ These parameters have been suppressed. However, we shall use the partial derivative $\partial h / \partial I$ to denote $\partial h\left(I, S, t_{1}\right) / \partial I$ evaluated at $S=t_{1}=0$. 
We know that $x_{1}=-v_{1} / v_{y}$. Differentiating with respect to $h$, we obtain:

$$
\frac{\partial x_{1}(P, y, h)}{\partial h}=-\frac{1}{v_{y}}\left(v_{h 1}-\frac{v_{h y} v_{1}}{v_{y}}\right),
$$

which is evaluated at the initial consumption point. Inserting this result into (31) we obtain:

$$
h_{\mathrm{t}_{1}}-h_{S}=\frac{v_{y}}{v^{\prime \prime}} \frac{\partial x_{1}(P, y, h)}{\partial h}\left(1-a \frac{\partial h}{\partial I}\right) .
$$

Under the assumptions which have been made, $a$ and $I$ are positively related. By definition $I=a h$, which implies that $1-a \partial h / \partial I=h \mathrm{~d} a / \mathrm{d} I>0$.

From the second-order condition of the individual optimum we know that $v^{\prime \prime}<0$. It then follows from (24) and (32) that:

$$
\begin{aligned}
& \frac{\partial x_{1}}{\partial h}>0, \text { for all } a \Rightarrow \frac{\partial W}{\partial t_{1}}<0, \\
& \frac{\partial x_{1}}{\partial h}=0, \text { for all } a \Rightarrow \frac{\partial W}{\partial t_{1}}=0 \\
& \frac{\partial x_{1}}{\partial h}<0, \text { for all } a \Rightarrow \frac{\partial W}{\partial t_{1}}>0
\end{aligned}
$$

Analogous results may, of course, be derived for $x_{2}, \ldots, x_{n}$. Thus, there are certain demand patterns which uniquely determine whether a small tax or subsidy on a commodity should be recommended. The partial derivative of the conditional demand function, $\partial x_{1}(P, y, h) / \partial h$, expresses the effect on the demand for $x_{1}$ when an individual who is initially optimally adjusted is forced to work a little more without any change in disposable income. A detailed discussion of conditional demand functions is found in Pollak (1969). Adopting his terminology, we say that

(a) if $\partial x_{i} / \partial h>0, x_{i}$ is positively related to $h$,

(b) if $\partial x_{i} / \partial h=0, x_{i}$ is unrelated to $h$, and

(c) if $\partial x_{i} / \partial h<0, x_{i}$ is negatively related to $h$.

We can now state:

Proposition 1. Starting from a situation in which an optimal income tax is the only tax, a welfare gain is achieved by imposing a (positive) marginal excise tax on a commodity which is negatively related to labour and by introducing a marginal subsidy on a commodity which is positively related to labour. 
In other words, commodities one typically buys more (less) of if more leisure is obtained without any loss of income, are candidates to be taxed (subsidized). This is a very simple result, although it may not be quite as simple to determine in practice what kind of relationship holds true for a particular commodity.

Proposition 1 gives a more precise meaning to the results of Meade (1955). A precise meaning has been assigned to Meade's references to 'substitutes for leisure' and 'things which are jointly demanded with leisure'. The relevant relations between the demand for various goods and the demand for leisure (or labour supply) are those precisely defined by Pollak (1969) as stated above. In a rough sense these relations are a kind of complement and substitute concepts, which are akin to but not identical to the usual Hicksian concepts used by Corlett and Hague. With this background it is interesting to explore further the various relations between leisure and the demand for the various commodities, which we now do.

\section{The roles of substitutes, complements and quasi-separability}

It may be interesting to relate the results of this paper to the conventional substitute and complement concepts. This may be helpful when trying to trace the effects of working time on demand, and it may reveal to what extent the results of the simple Corlett-Hague model carry over to the more complicated model of mixed taxation studied in the current paper and in modern tax theory.

The simplest procedure is to establish directly the relationship between the Pollak concepts and the Hicksian concepts. Let us consider the conditional demand function,

$$
x_{i}(P, a h-T(a h), h),
$$

at the unconditional equilibrium; that is where $h$ is optimally adjusted to the price and tax parameters. Let $m$ denote the marginal wage rate:

$$
m=a\left(1-T^{\prime}\right)
$$

The effect of a change in $m$ on $x_{i}$ is found by differentiating (34):

$$
\frac{\partial x_{i}}{\partial m}=\frac{\partial x_{i}}{\partial y} m \frac{\partial h}{\partial m}+\frac{\partial x_{i}}{\partial h} \frac{\partial h}{\partial m} .
$$

Hence:

$$
\frac{\partial x_{i}}{\partial h}=\frac{\partial x_{i} / \partial m}{\partial h / \partial m}-m \frac{\partial x_{i}}{\partial y}
$$


It is well known that the labour supply responds positively to a higher marginal wage rate so that $\partial h / \partial m>0$. For convenience let us rule out inferior goods so that $\partial x_{i} / \partial y>0$. Then we see that if $x_{i}$ and $h$ are substitutes, $\partial x_{i} / \partial m<0$, then $x_{i}$ is negatively related to $h$ in the Pollak sense. $x_{i}$ is negatively related to $h$ if they are 'weak' complements, and positively related to $h$ if they are 'strong' complements. Thus, we find that a complement with leisure (substitute for labour) should be taxed and so should a sufficiently weak substitute for leisure, while a strong enough substitute for leisure should be subsidized from our tax reform point of view. Likewise the demand for a complement with or sufficiently weak substitute for leisure should be discouraged in the Mirrlees sense at the full optimum, while the demand for a strong enough substitute for leisure should be encouraged (see section 8 below). We may note that the effects pointed out by Corlett and Hague do play a crucial role, even in the present context.

An alternative way to relate our results to the roles of substitutes and complements may bring out more clearly how the various effects arise. It starts out considering the crucial difference $\left(h_{t_{i}}-h_{S}\right)$ of formula (24). Each term may be decomposed into a compensated effect and an income effect:

$$
\begin{aligned}
h_{t_{i}}-h_{S} & =\left.h_{t_{i}}\right|_{u}+\text { income effect }-\left.h_{S}\right|_{u}-\text { income effect } \\
& =\left.h_{t_{i}}\right|_{u}-\left.h_{S}\right|_{u},
\end{aligned}
$$

since the shift is designed in such a way that the income effects are equal and cancel out. From the definition $m=a\left(1-T^{\prime}\right)$ it follows that:

$$
\frac{\partial m}{\partial S}=-a \frac{\partial T^{\prime}}{\partial S} .
$$

Making use of the assumption that $T_{S}=x_{i}$, we find that:

$$
\frac{\partial T^{\prime}}{\partial S}=\frac{\partial T_{S}}{\partial I}=\frac{\partial x_{i}}{\partial I} .
$$

Fqs. (38) and (39) together imply that:

$$
\frac{\partial m}{\partial S}=-a \frac{\partial x_{i}}{\partial I} .
$$

Hence we can derive:

$$
\left.h_{S}\right|_{u}=\frac{\partial h}{\partial m} \frac{\partial m}{\partial S}=-\frac{\partial h}{\partial m} a \frac{\partial x_{i}}{\partial I} .
$$


We insert this result into (37) and obtain:

$$
h_{t_{i}}-h_{S}=\left.\frac{\partial h}{\partial t_{i}}\right|_{u}+\frac{\partial h}{\partial m} a \frac{\partial x_{i}}{\partial I},
$$

where the sign of the compensated derivative $\left.\left(\partial h / \partial t_{i}\right)\right|_{u}$ defines whether $h$ and $x_{i}$ are substitutes or complements. The presence of $\partial x_{i} / \partial I$ in (42) shows that a sort of income effect is important. It should be noted that this effect arises only because it determines the change in the marginal after-tax wage-rate which in turn has a pure substitution effect. The greater the inequality aversion of the government, the steeper will the initial income tax schedule tend to be. If a tax is levied on a commodity of which high-income people will buy far more than low-income people, the stcepness of the income tax schedule can be reduced significantly without changing the overall distributional profile of the tax policy. Hence, the marginal income tax is reduced with favourable effects on efficiency. This is exactly what is expressed by the second term of (42).

If the choice of commodity taxes is approached in terms of ordinary Hicksian substitute and complement concepts, one must also allow for the income effect on commodity demand discussed above, which in general may be positive or negative. In this sense Meade was right in making his qualification about the distributional impact of a commodity tax. If sufficiently adverse (from an egalitarian point of view) it may, as noted by Meade, dominate the otherwise advantageous effect of a tax on a complement with leisure.

The role of the income effect may be related to the tax results obtained in the case of quasi-separability [see Deaton (1981)]. Goods $i$ and $j$ are said to be quasi-separable from leisure (work) if the marginal rate of substitution between good $i$ and good $j$ is independent of leisure (work) along an indifference curve, if the consumer is compensated for the change in leisure (work) by a proportional change in the vector of all goods (including leisure). An important implication of quasi-separability is that compensated changes in the wage-rate affect commodity demands proportionately. Since a sole change in the marginal wage-rate is equivalent to a compensated change in the wage-rate, we have that in the case of quasi-separability:

$$
\partial x_{i} / \partial m=\delta x_{i}
$$

where $\delta$ is independent of $i$. We can then reformulate (36) to obtain:

$$
\frac{\partial x_{i} / \partial h}{x_{i}}=\frac{\delta}{\partial h / \partial m}-\frac{m}{y} \frac{\partial x_{i}}{\partial y} \frac{y}{x_{i}}
$$


The message derived from this formula is that commodity taxes should be levied on commodities with sufficiently high income elasticities, as may be the case for a typical luxury. This result bears a certain resemblance to the finding that progressive (non-linear) commodity taxation is desirable under quasi-separability [Deaton $(1981$, p. 1249)]. This means that the tax-rate should be higher the more luxurious one finds a good, in the sense that it is more highly valued by people on high utility levels than by people on less favourable indifference curves. It also seems interesting to relate the results of the present analysis to those of Atkinson and Stiglitz (1976) and Mirrlees (1976), as will be done in the following two sections.

\section{Comparison with Atkinson and Stiglitz}

From Atkinson and Stiglitz (1976) we know that commodity taxes are always non-optimal regardless of how the population is composed if the utility function is of the weakly separable form $u(\phi(x), h)$ so that $\partial\left(u_{i} / u_{1}\right) / \partial h=0$ for all $i$. It is easy to verify that this is equivalent to $\partial x_{i} / \partial h=0$ for all $i$, as indeed it should be if our results are correct. This equivalence sheds new light on the Atkinson-Stiglitz result.

The optimality conditions for $x$ when $h$ is given are:

$$
\begin{aligned}
& \frac{u_{j}}{u_{1}}=\frac{P_{j}}{P_{1}}, \quad \forall j, \\
& \frac{y}{P_{1}}=\frac{1}{P_{1}} P x .
\end{aligned}
$$

Let us introduce the notation $x_{j}^{\prime}=\partial x_{j} / \partial h$. Differentiating the equation system (45) and (46) we obtain the system:

$$
\begin{aligned}
& \left(\frac{\partial}{\partial x_{1}} \frac{u_{2}}{u_{1}}\right) x_{1}^{\prime}+\left(\frac{\partial}{\partial x_{2}} \frac{u_{2}}{u_{1}}\right) x_{2}^{\prime}+\ldots+\left(\frac{\partial}{\partial x_{n}} \frac{u_{2}}{u_{1}}\right) x_{n}^{\prime}=-\frac{\partial}{\partial h} \frac{u_{2}}{u_{1}}, \\
& \left(\frac{\partial}{\partial x_{1}} \frac{u_{3}}{u_{1}}\right) x_{1}^{\prime} \ldots=-\frac{\partial}{\partial h} \frac{u_{3}}{u_{1}}, \\
& \quad \vdots \\
& \left(\frac{\partial}{\partial x_{1}} \frac{u_{n}}{u_{1}}\right) x_{1}^{\prime} \ldots=-\frac{\partial}{\partial h} \frac{u_{n}}{u_{1}}, \\
& x_{1}^{\prime}+\frac{u_{2}}{u_{1}} x_{2}^{\prime}+\ldots+\frac{u_{n}}{u_{1}} x_{n}^{\prime}=0 .
\end{aligned}
$$


We immediately see that:

$$
\frac{\partial\left(u_{j} / u_{1}\right)}{\partial h}=0, \text { for all } j \Leftrightarrow \frac{\partial x_{j}}{\partial h}=0, \text { for all } j .
$$

Eq. (48) allows us to state:

Proposition 2. The demand pattern $\partial x_{j} / \partial h=0$, for all $j$, obtains if and only if the utility function belongs to the class of weakly separable utility functions $u(\phi(x), h)$.

For later application it is useful to solve the equation system of the twogood casc using commodity 2 as the numeraire:

$$
\begin{aligned}
& \frac{\partial x_{1}}{\partial h}=\frac{\partial\left(u_{1} / u_{2}\right)}{\partial h} \frac{1}{D} \\
& \frac{\partial x_{2}}{\partial h}=-\frac{\partial\left(u_{1} / u_{2}\right)}{\partial h} \frac{u_{1}}{u_{2}} \frac{1}{D}
\end{aligned}
$$

where

$$
D=-\left|\begin{array}{cc}
\frac{\partial}{\partial x_{1}} \frac{u_{1}}{u_{2}} \frac{\partial}{\partial x_{2}} \frac{u_{1}}{u_{2}} \\
\frac{u_{1}}{u_{2}} & 1
\end{array}\right|
$$

As usual, $u$ is assumed to be strictly quasi-concave in $x_{1}$ and $x_{2}$, which implies that $D>0$.

\section{Comparison with Mirrlees}

Mirrlees (1976) established conditions for optimal mixed taxation consisting of income and commodity taxation. His analysis is presented in a very general form. Let us now consider the case in which simultaneous optimization of a non-linear income tax and excise tax rates on the various commodities takes place.

Sticking to the notation of the current paper, we can write the demand functions used by Mirrlees as:

$$
x_{i}(P, y, I, a)
$$

(with $P, I$ and $a$ replacing $q, z$ and $n$, respectively). Let us define 


$$
\left.\frac{\mathrm{d} x_{i}}{\mathrm{~d} P_{k}}\right|_{u}=x_{i k}^{\mathrm{c}}
$$

which denotes the compensated derivative of $x_{i}$ with respect to $P_{k}$.

In our notation the following necessary optimum conditions derived by Mirrlees can be established:

$$
e_{i} \equiv \int \sum_{k} x_{i k}^{\mathrm{c}} t_{k} f(a) \mathrm{d} a=-\int \nu(a) \frac{\partial x_{i}(P, y, I, a)}{\partial a} \mathrm{~d} a, \quad i=1, \ldots, n,
$$

where $v(a)>0$ [Mirrlees (1976, eq. (9.86))].

Adopting Mirrlees' own interpretation, $e_{i}$ is a measure of the extent to which commodity taxes encourage consumption of the different commodities. Then $\partial x_{i} / \partial a>0$ implies that the consumption of commodity $i$ should be discouraged, while $\partial x_{i} / \partial a<0$ implies that it should be encouraged.

The results of Mirrlees apply to the full optimum, while the analysis of the preceding sections of this paper is concerned with the introduction of small excise taxes to supplement the income tax. However, the results are closely related to each other. To see this, rewrite $(51)$ in the following way:

$$
\begin{aligned}
x_{i}(P, y, I, a) & \equiv x_{i}(P, y, I / a) \\
& \equiv x_{i}(P, y, a h / a) \equiv x_{i}(P, y, h),
\end{aligned}
$$

which is identical to the conditional demand function (6). We immediately see that:

$$
\frac{\partial x_{i}(P, y, I, a)}{\partial a}=-\frac{\partial x_{i}(P, y, h)}{\partial h} \cdot \frac{h}{a}
$$

We can therefore say that if $x_{i}$ is negatively related to $h$, the consumption of commodity $i$ should be discouraged by the optimum excise taxes, while if $x$, is positively related to $h$, the demand for commodity $i$ should be encouraged by the optimum excise taxes.

Condition (53) was explained by Mirrlees (1976, p. 347) in the following words: 'This surprisingly simple criterion says that commodity taxes should bear more heavily on the commodities high- $a$ individuals have relatively strongest tastes for.' We have seen that a good is negatively related to labour if a reduction in hours worked, holding income constant, results in an increase in demand for the good. Such a reduction in hours worked with constant income can be achieved by increasing ability. It is in this sense that a good that is negatively related to labour is a good for which people of higher abilities have 'strongest tastes'. 


\section{Leisure goods and the Becker-Lancaster approach}

In much of the literature on excise taxes and tax-distorted labour supply a special importance is attached to leisure goods. It is typical that after showing that there is no need to employ differentiated indirect taxation in the presence of a weakly separable utility function, Atkinson and Stiglitz (1980) make the following comment: '... and it is quite possible that this separability requirement may not in practice be met, for example, in the case of leisure goods'. This comment leads to no further conclusion. But it seems to be a popular belief among many economists that taxation of leisure goods should be recommonded. It is thereforc interesting to discuss whether this is an implication of the tax theory.

An approach to the relationship between working time (or leisure) and market goods which may be useful for this purpose, is the Becker-Lancaster approach [Becker (1965) and Lancaster (1966)]. The key idea of this approach is that the basic goods enjoyed by a consumer are produced in the household by means of own effort and commodities purchased in the market. Recreation may be one such basic good which is produced by means of a certain input of time (leisure) and leisure goods.

We shall consider a simple case where utility is derived from two basic goods, of which one is recreation and the other is simply a market commodity. The enjoyment of the latter is assumed not to be time consuming. Let $z$ denote the amount of recreation. Leisure, $r$, is the amount of time spent on recreation. Commodity 1 is now interpreted as the market good used as an input in the production of $z$. The household production of recreation is described by the technology function:

$$
z\left(x_{1}, r\right)
$$

Partial derivatives are denoted by $z_{x}$ and $z_{r}$ and are assumed to be positive. $x_{1}$ may consist of sporting equipment, travelling, tickets for concerts or amusement parks, etc.

The relationship between $r$ and $h$ is given by the time budget:

$$
r+h=k=\text { constant }
$$

The utility function is now written as:

$$
u\left(z\left(x_{1}, r\right), x_{2}, h\right)=u\left(z\left(x_{1}, k-h\right), x_{2}, h\right)
$$

which is basically a function of $x_{1}, x_{2}$ and $h$, as before. Note that $h$ enters twice, once because of its opportunity cost through the time budget and once because work may be disliked or enjoyed as such. The following notation is used: 


$$
\begin{aligned}
& u_{z}=\frac{\partial u}{\partial z}, \quad u_{i}=\frac{\partial u}{\partial x_{i}}, \quad i=1,2 \\
& z_{x r}=\frac{\partial^{2} z}{\partial x_{1} \partial r}
\end{aligned}
$$

As was discussed in section 7 , a small excise tax on $x_{1}$ should be recommended or not depending on the sign of $\partial\left(u_{1} / u_{2}\right) / \partial h$. We easily find that:

$$
\frac{u_{1}}{u_{2}}=\frac{u_{z} z_{x}}{u_{2}}
$$

Then the following expression is obtained:

$$
\frac{\partial\left(u_{1} / u_{2}\right)}{\partial h}=-z_{x r} \frac{u_{z}}{u_{2}}-\frac{\partial\left(u_{z} / u_{2}\right)}{\partial z} z_{x} z_{r}+\frac{\partial\left(u_{z} / u_{2}\right)}{\partial h} z_{x},
$$

where both effects of $h$ are allowed for. Let us consider the terms in reversed order. The last term expresses how the marginal valuation of recreation changes with work effort. It seems natural to assume that this effect is nonnegative. Probably recreation is more highly valued the harder a person works. For a given labour supply $\partial\left(u_{z} / u_{2}\right) / \partial z<0$ if $x_{2}$ is a normal good, which seems to be a natural assumption, especially at this level of aggregation. If $x_{1}$ and $r$ are technically independent, $z_{x r}=0$, or technical substitutes, $z_{x r}<0$, the first term on the right-hand side is non-negative, and the whole expression becomes positive. If $x_{1}$ and $r$ are technical complements, $z_{x r}>0$, the overall sign is positive if $x_{1}$ and $r$ are sufficiently weak complements, and negative if they are sufficiently strong complements in a technological sense. Thus, a small excise tax on $x_{1}$ should be recommended only if $x_{1}$ and leisure are strong technical complements. Otherwise a small subsidy should be recommended.

It follows that it is not necessarily appropriate to recommend taxation of leisure goods, even if one is willing to make the tempting assumption that they are technical complements with leisure within a Becker--Lancaster framework. The notion behind the belief that leisure goods should be taxed is presumably that by making leisure goods more expensive, recreation is made less attractive and so is leisure time. The weak point in this argument is that even if recreation becomes less attractive compared to other goods, leisure goods may be substituted by leisure time in the production of recreation, and the labour supply may shrink. Recreation may simply be made more time-intensive and less commodity-intensive. As an extreme 
example a long cheap cottage holiday may be substituted for a short serviceintensive luxury cruise.

We may explore this matter further after adding a few more simplifying assumptions which reduce the efforts needed to bring out the main point. Utility is assumed to be a function of $z$ and $x_{2}$ only, which means that there is no utility or disutility from work effort per se. This utility function is assumed to be homothetic. The technology function $z$ is assumed to be homogeneous of degree one. The respective marginal rates of substitution can be expressed as:

$$
\frac{u_{z}}{u_{2}}=\alpha\left(\frac{x_{2}}{z}\right)
$$

and

$$
\frac{z_{x}}{z_{r}}=\beta\left(\frac{r}{x_{1}}\right)
$$

where $\alpha$ and $\beta$ are both increasing functions.

The elasticities of these functions are denoted by $\hat{\alpha}$ and $\hat{\beta}$. We also define the elasticities of substitution:

$$
\sigma_{u}=1 / \hat{\alpha}
$$

and

$$
\sigma_{z}=1 / \hat{\beta}
$$

In order to focus on demand properties, taxes are left on one side. The budget constraint of the consumer then becomes:

$$
P_{1} x_{1}+P_{2} x_{2}=a h
$$

The optimum choice of the consumer is determined by eq. (65):

$$
\begin{aligned}
& \alpha\left(\frac{x_{2}}{z}\right)=\frac{P_{1}}{P_{2} z_{x}}, \\
& \beta\left(\frac{r}{x_{1}}\right)=\frac{P_{1}}{a},
\end{aligned}
$$

and

$$
z\left(x_{1}, r\right)=z
$$


In order to study compensated effects, utility is assumed to be constant:

$$
u\left(z, x_{2}\right)=\text { constant }
$$

Let $\varepsilon_{1}$ and $\varepsilon_{2}$ denote the partial elasticities of $z$. Also, let $\hat{z}_{x}$ denote the partial elasticity of $z_{x}$ with respect to $x_{1}$. Since $z_{x}$ is homogeneous of degree zero, the partial elasticity of $z_{x}$ with respect to $r$ is $-\hat{z}_{x}$. Let a caret ( ${ }^{\wedge}$ ) over $x_{1}, x_{2}$, $z$ and $r$ denote the compensated elasticity with respect to $P_{1}$. The elasticities are derived by means of the equation system (66)-(69). We find that:

$$
\begin{aligned}
& \hat{x}_{2}-\hat{z}=\sigma_{u}+\sigma_{u} \hat{z}_{x}\left(\hat{r}-\hat{x}_{1}\right), \\
& \hat{r}-\hat{x}_{1}=\sigma_{z}, \\
& \varepsilon_{1} \hat{x}_{1}+\varepsilon_{2} \hat{r}=\hat{z},
\end{aligned}
$$

and

$$
\frac{u_{z} z}{u} \hat{z}+\frac{u_{2} x_{2}}{u} \hat{x}_{2}=0
$$

which is equivalent to:

$$
\frac{P_{1} z}{P_{2} x_{2} z_{x}} \hat{z}+\hat{x}_{2}=0
$$

From (71) and (72) we get:

$$
\hat{r}=\varepsilon_{1} \sigma_{z}+\hat{z}
$$

We see that even if the effect of a higher $P_{1}$ is to make $z$ less attractive, $\hat{z}<0$, $r$ may still rise because of the positive substitution term $\varepsilon_{1} \sigma_{z}$. From (70), (71), and (73):

$$
\hat{z}=\frac{-1}{\gamma}\left(\sigma_{u}+\sigma_{u} \sigma_{z} \hat{z}_{x}\right)
$$

where

$$
\gamma=1+\frac{P_{1} z}{P_{2} x_{2} z_{x}}
$$

Combining (74) and (75), we get:

$$
\frac{\hat{r}}{\sigma_{u}}=\left(\frac{\varepsilon_{1}}{\sigma_{u}}+\frac{-\hat{z}_{x}}{\gamma}\right) \sigma_{z}-\frac{1}{\gamma} .
$$


$\hat{z}_{x}$ is assumed to be negative so that the term in parentheses is positive. Hence, we see that the substitution properties of the $z$-function are crucial in determining the sign of $\hat{r}$.

If $\sigma_{z}$ is big enough so that substitution possibilities are good, $\hat{r}$ will become positive, because a higher $P_{1}$ motivates a large-scale substitution of $x_{1}$ by $r$. Thus, $x_{1}$ and leisure become substitutes, even though they are used jointly to produce recreation. If $\sigma_{z}$ is small enough so that substitution possibilities dwindle, $\hat{r}$ obviously becomes negative, and $x_{1}$ and $r$ are complements.

Substitution between leisure time and leisure goods is a complication which must be carefully allowed for when excise taxes on leisure goods are considered. This is not to argue that leisure goods should be left untaxed. A number of leisure goods are probably not easily substituted by leisure time. And even if a commodity is a substitute for leisure, we know from section 6 that it may be desirable to tax this commodity if the substitution property is moderate. Hence, there is good reason to believe that many leisure goods should be taxed. But a general prescription to this effect may easily prove too hasty. Which specific commodities show such demand properties that they should be taxed (subsidized) is, of course, an empirical question which is not going to be pursued any further in this paper.

\section{Conclusion}

Within a tax-theoretical framework and starting from a situation in which an optimal income tax is the only tax, this paper has analysed which commodities should be taxed (subsidized) if small excise taxes may be levied and the income tax adjusted to keep total tax revenue unchanged. The answer is simple. A commodity should be taxed (subsidized) if it is positively (negatively) related to leisure in the Pollak sense, which means that more (less) of the good is consumed if more leisure is obtained at constant income. Furthermore, it was shown that the result of Atkinson and Stiglitz, that no excise taxes should be levied if the utility function exhibits weak separability between leisure and all other goods together, simply means that if all commodities are unrelated to leisure in the Pollak sense, no commodity should be taxed (or subsidized). It was also demonstrated that the sign of the same relation determines whether the consumption of a commodity should be encouraged or discouraged in the Mirrlees sense when the income tax and excise taxes are all set optimally. ${ }^{7}$ The analysis has provided a link between the older analyses by Corlett and Hague and by Meade and modern optimum tax theory on the roles of direct and indirect taxation.

The analysis has been confined to circumstances where all essential functions are differentiable. This approach, sharcd with a number of other analyses in this field, has allowed the use of ordinary differential calculus.

\footnotetext{
${ }^{7}$ See Mirrlees (1976, p. 347).
} 
Although of limited generality, it seems that differentiable cases can contribute to our insight into the optimum choice of commodity taxes to supplement the income tax, and thus have a fair claim for interest.

The partial nature of the analysis should be noted. The choice between direct and indirect taxation has a number of interesting aspects, of which the effect on labour incentives, focused on above, is only one. The argument for excise taxes most firmly rooted in economic theory is, of course, the externality argument for Pigouvian taxes. This aspect is well known and hardly needs elaboration. It has therefore been suppressed in the present context. Two aspects have received little attention in the theoretical literature so far. One is the choice of excise taxes when savings decisions are distorted by income taxation, and the other is the implications of tax evasion for the choice between direct and indirect taxation. Further exploration of these aspects within the framework of optimum tax theory or tax reform theory would certainly be worthwhile in order to broaden the basis of economic advice in this practically and politically important field.

\section{References}

Atkinson, A.B., 1977, Optimal taxation and the direct versus indirect tax controversy, Canadian Journal of Economics 10, 590-606.

Atkinson, A.B. and J.E. Stiglitz, 1976, The design of tax structure: Direct versus indirect taxation, Journal of Public Economics 6, 55-75.

Atkinson, A.B. and J.E. Stiglitz, 1980, Lectures on public economics (McGraw-Hill, London).

Becker, G.S., 1965, A theory of the allocation of time, Economic Journal 75, 493-517.

Corlett, W.J. and D.C. Hague, 1953-54, Complementarity and the excess burden of taxation, Review of Economic Studies 21, 21-30.

Deaton, A., 1981, Optimal taxes and the structure of preferences, Econometrica 49, 1245-1260.

Lancaster, K.J., 1966, A new approach to consumer theory, Journal of Political Economy 74, $132-157$.

Meade, J.E., 1955, Trade and welfare (Oxford University Press, London).

Mirrlees, J.A., 1971, An exploration in the theory of optimum income taxation, Review of Economic Studies 38, 175-208.

Mirrlees, J.A., 1975, Optimal commodity taxation in a two-class economy, Journal of Public Economics 4, 27-33.

Mirrlees, J.A., 1976, Optimal tax theory: A synthesis, Journal of Public Economics 6, 327-358.

Mirrlees, J.A., 1977, The theory of optimal taxation, in: K.J. Arrow and M.D. Intrilligator, eds., Handbook of mathematical economics (North-Holland, Amsterdam).

Pollak, R.A., 1969, Conditional demand functions and consumption theory, Quarterly Journal of Economics, 60-78.

Sandmo, A., 1976, Optimal taxation: An introduction to the literature, Journal of Public Economics 6, 37-54.

Seade, J., 1982, On the sign of the optimum marginal income tax, Review of Economic Studies $49,637-643$. 